Disponível em:

http://editora.unoesc.edu.br/index.php/race

RACE, Joaçaba, v. 16, n. 2, p. 505-522, maio/ago. 2017

\title{
ANÁLISE DOS CUSTOS AMBIENTAIS RELACIONADOS COM A GESTÃO DE RESÍDUOS EM INDÚSTRIAS QUÍMICAS
}

Analysis of the environmental costs related to waste management in chemical industries

Margareth Aparecida Moraes

E-mail: margarethm@feevale.br

Mestre em Qualidade Ambiental pela Universidade Feevale; Pós-graduada em Auditoria e Perícia pela Universidade Feevale; Professora na Universidade Feevale; Membro da Junta de Recursos Fiscais da PMNH.

Vanessa Theis

E-mail: nessa.theis@gmail.com Doutoranda e Mestre em Qualidade Ambiental na Universidade Feevale.

Margarete Blume Vier E-mail: marga_vier@hotmail.com

Graduanda do Curso de Ciências Contábeis e Bolsista de Iniciação Científica da Universidade Feevale; Servidor Público (Auxiliar Administrativo) na Prefeitura do Município de Dois Irmãos.

Dusan Schreiber

E-mail: dusan@feevale.br Doutor em Administração pela Universidade Federal do Rio Grande do Sul; Mestre em Administração pela Universidade do Vale do Rio dos Sinos; Professor e pesquisador do Programa de Pós-graduação em Qualidade Ambiental e Graduação em Administração na Universidade Feevale.

Endereço para contato: ERS 239, 2755, Vila Nova, 93525-075, Novo Hamburgo,

Rio Grande do Sul, Brasil.

Artigo recebido em 26 de outubro de 2016. Aceito em 10 de fevereiro de 2017. 


\section{Resumo}

Com a existência de um limite entre o esgotamento dos recursos naturais e do crescimento econômico, evidencia-se a necessidade de encontrar meios para compatibilizar a conservação ambiental e o crescimento econômico. Nesse cenário, desponta a gestão ambiental, que visa reduzir os impactos causados ao meio ambiente advindos das atividades econômicas das empresas. Cumpre destacar que a geração de resíduos se apresenta como aspecto indissociável do processo industrial, que demanda investimentos para a sua adequada destinação final. Nesse contexto, o objetivo com este trabalho foi analisar os custos ambientais relacionados com a gestão de resíduos em indústrias químicas localizadas na região metropolitana de Porto Alegre. Os dados foram coletados por meio de uma pesquisa survey com gestores de 36 empresas da unidade de análise. As evidências coletadas facultaram a constatação de que os resíduos representam a maior parte dos passivos ambientais nas empresas investigadas. Além disso, grande parte dos respondentes declarou que nas empresas que desenvolvem suas atividades, os passivos são tratados por meio da comercialização dos resíduos gerados pelo processo produtivo, a fim de obter receita adicional. De acordo com 24 respondentes, os resíduos sólidos gerados em um processo produtivo são reaproveitados na produção de outro produto, e os gestores que responderam que não conseguem sequer gerar receita adicional, via comercialização de resíduos, tampouco aproveitar resíduos na fabricação de outro produto, alegaram dificuldade operacional para viabilizar o referido modelo, ou falta de organização interna para mapear os resíduos sólidos gerados no processo.

Palavras-chave: Gestão de resíduos. Custos ambientais. Indústria química.

\section{Abstract}

With the existence of a limit between the exhaustion of natural resources and the economic growth, it is highlighted the need to find ways to reconcile environmental conservation and economic growth. In this scenario, comes up environmental management, which aims to reduce the impacts to the environment arising from the economic activities of enterprises. It should be noted that the generation of waste is presented as an inseparable aspect from the manufacturing process, which requires investments for its proper disposal. In this context, the aim of this study was to analyze the environmental costs related to waste management in chemical industries located in the metropolitan area of Porto Alegre. The data were collected through a survey research with managers of 36 companies unit analysis. Evidence collected provided the realization that the waste represent most of the environmental damage in the investigated companies. In addition, most respondents stated that in companies that develop their activities, liabilities are treated through the marketing of waste generated by the production process in order to obtain additional revenue. According to 24 respondents, the solid waste generated in a production process are reused in the production of another product, and the managers who responded that they cannot even generate additional revenue via marketing waste, either take 
advantage of waste in the manufacture of another product, alleged operational difficulty to enable that model, or lack of internal organization to map the solid waste generated in the process. Keywords: Wastes. Environmental economics. Chemical industry.

\section{INTRODUÇÃO}

Observando-se a história da humanidade, percebe-se que a preocupação com o meio ambiente é recente e que os recursos naturais do Planeta foram sendo esgotados indiscriminadamente. Foi a partir da década de 1960 que o mundo percebeu que o descaso com as emissões de poluentes e o crescimento da população e do consumo poderiam levar a natureza ao colapso, com repercussão direta sobre a manutenção da vida humana no Planeta. Ademais, a busca pela proteção ambiental estimulou a realização da Conferência de Estocolmo, na Suécia, em 1972, onde diversos chefes de governos se reuniram para debater sobre as questões ambientais no mundo (MOURA, 2004).

Os debates que se iniciaram naquele período evidenciaram a complexidade subjacente às possíveis alternativas de solução para reduzir o ritmo de degradação do meio ambiente. Assim, verifica-se que as dimensões econômicas e mercadológicas das questões ambientais mostram-se cada vez mais relevantes. Nesse sentido, as

ações em defesa do meio ambiente vêm ganhando força no ciclo produtivo industrial, assumindo função de cunho estratégico por constituírem um fator de diferencial competitivo sustentável.

As mudanças relacionadas com a melhoria da qualidade do meio ambiente, especialmente nas organizações, resultam em produtos que impactam minimamente o meio ambiente, facultando o surgimento de uma nova consciência ambiental e de um conjunto de práticas organizacionais e sociais. Nesse sentido, não há como os gestores organizacionais pensarem no planejamento estratégico de suas organizações sem nele incluir a variável ambiental, a qual, segundo Moura (2004), incorpora a perspectiva de desenvolvimento sustentável, preocupando-se com a manutenção de estoques de recursos naturais, qualidade de vida e uso adequado do solo, além do aspecto da conservação e sistemas naturais.

Além disso, a gestão ambiental passa a ser incorporada nas atividades diárias das empresas, acompanhada da preocupação com a degradação ambiental que as atividades organizacionais podem ocasionar e com as diversas normas protetivas do meio ambiente a serem observadas. Um dos segmentos econômicos mais afetados pela regulação social, voltada a assegurar a melhoria da qualidade ambiental, é o de indústrias químicas (ASSOCIAÇÃO BRASILEIRA DA INDÚSTRIA QUÍMICA, 
2015). Por ter um alto potencial de impacto ambiental, principalmente em razão dos resíduos gerados no processo produtivo, o legislador estabeleceu normas rígidas, o que exigiu das organizações do setor em tela investimentos relevantes para a sua adequação, além de aumentar os custos para a manutenção dos sistemas ambientais.

Diante dessa percepção mercadológica, neste trabalho teve-se como objetivo geral a análise dos custos ambientais relacionados com a gestão de resíduos em indústrias químicas localizadas na região metropolitana de Porto Alegre. A pesquisa no segmento da indústria química se justifica em decorrência da sua importância nos demais setores da economia, isto é, o segmento químico está presente em praticamente todas as atividades econômicas brasileiras. Além disso, o estudo pode ser considerado relevante, pois o referido segmento apresenta um grande potencial de impacto ambiental e é objeto frequente de iniciativas de regulamentações relacionadas às questões ambientais.

\section{CONTABILIDADE AMBIENTAL}

As empresas, ao realizarem as atividades que fazem parte da sua operação, devem minimizar os custos e com isso obter maior lucratividade. Contudo, uma perspectiva diferente sobre a gestão ambiental se faz necessária, considerando os controles ambientais indispensáveis em um processo produtivo. Assim, as atividades de preservação, controle, reciclagem e recuperação do meio ambiente passam a fazer parte da contabilidade de uma empresa, preocupando-se em mensurar e analisar um processo produtivo sustentável vinculado às estratégias competitivas empresariais.

Para Ribeiro (2006), a contabilidade ambiental é um complemento da contabilidade, sendo apenas acrescentadas as contas contábeis que receberam escrituração dos fatos ambientais ocorridos, tendo como propósito evidenciar custos ligados à recuperação, preservação e proteção ambiental. Nesse sentido, a contabilidade ambiental passa a ser um diferencial competitivo nas empresas, considerando que elas utilizam os recursos ambientais e lançam no meio ambiente os resíduos decorrentes de sua produção, prestando-se também a atender às prerrogativas legais.

Cabe destacar estudo realizado por Leonardo (2006) referente aos fatores que motivam as indústrias químicas brasileiras a adotarem a gestão de custos ambientais. Os dados coletados pelo autor revelam que a imagem é o fator apontado por todas as empresas como determinante na preocupação com o meio ambiente. Ligado a esse motivo está o atendimento aos mercados nacional e internacional. As empresas atentam-se ao mercado internacional, em que a variável ambiental se firma como deter- 
minante para a competitividade e imagem das organizações, sobretudo para setores controversos como o da indústria química.

Leone e Leone (2010) sinalizam a importância da sintonia entre o sistema de custos e a contabilidade da empresa na geração de informações geradas pelo sistema, possibilitando produzir bons resultados gerenciais e identificando os aspectos positivos que deverão ser mantidos pela organização, bem como os pontos fracos que necessitam atenção e reparo. Evidencia-se, assim, a importância da contabilidade no inter-relacionamento da empresa com o meio ambiente, ao demonstrar como o patrimônio da empresa é afetado pelas causas ambientais e como a empresa pode agir para reduzir ou até mesmo eliminar as agressões causadas pelas suas atividades ao meio ambiente, ações que promoverão a sustentabilidade ambiental (TINOCO; KRAEMER, 2011).

A gestão de custos ambientais somente pode ser realizada com sucesso se houver o envolvimento da alta direção e três áreas: gestão ambiental, finanças e contabilidade. Qualquer investimento na área ambiental deve ser visto como qualquer outro investimento dentro da empresa. "A qualidade ambiental, integrada ao sistema global da organização, pode e deve ser mensurada em termos de custos, embora existam, no início do processo, muitas dificuldades em se quantificar o que significa realmente qualidade ambiental” (MOURA, 2006, p. 69).

Em relação à gestão de custos ambientais, Sanches (1997) propõe a internalização de custos ambientais totais no processo de gestão financeira das organizações, com foco principal na determinação do ponto de equilíbrio ambientalmente ajustado. O processo de internalização desses custos ambientais representa uma ação de curto e médio prazo, que visa incorporar nas empresas a questão dos impactos ambientais de seus processos de produção, focando no longo prazo um movimento de conscientização mais abrangente e profundo.

A referida autora acredita que os gestores necessitam que a questão ambiental possua enfoque monetário para que o processo de análise dos impactos ambientais seja mais profundamente considerado e analisado. A partir do momento em que a empresa passa a ter um custo adicional voltado aos impactos do meio ambiente, sua atenção para diminuir esse custo ambiental pode contribuir para a redução da poluição e da diminuição do uso dos recursos naturais, tornando a organização ambientalmente eficiente. Essa eficiência ambiental, quando atingida, pode ser utilizada como um importante princípio de marketing e de responsabilidade social corporativa (SANCHES, 1997).

Ressalta-se que os custos ambientais se vinculam a ativos e passivos ambientais. Os ativos ambientais, segundo Silva (2009), são representados por todos os bens e direitos ligados à atividade ambiental da empresa, e os passivos ambientais 
são representados por todas as obrigações da empresa relacionadas ao meio ambiente. Assim, pode-se afirmar que tanto os ativos quanto os passivos ambientais estão incorporados no dia a dia de cada organização, podendo levá-la ao sucesso ou à perda de sua credibilidade no mercado atuante.

Ademais, Freitas et al. (2007) apontam que a empresa precisa ter, de forma estruturada em seu sistema de acumulação das informações contábeis, a escrituração dos custos ambientais, que podem refletir um ativo ou passivo ambiental. Cumpre destacar que o passivo ambiental em uma empresa está ligado à realização de investimentos em ações de controle, preservação e repercussão do meio ambiente e origina um ativo ou um custo ambiental (WAKIM; WAKIM, 2012). Assim, os gestores devem preocupar-se não apenas em minimizar os impactos ambientais das empresas, mas também em poder, por meio de métodos adotados contabilmente, ter uma valoração econômica dos bens e diminuição dos passivos ambientais, pois estes refletem na economia, no valor das ações e na perspectiva de conceito ambiental politicamente correta das medidas adotadas pela empresa.

Cabe lembrar que passivos ambientais se referem aos benefícios econômicos ou aos resultados que são sacrificados em razão da necessidade de preservar, proteger e recuperar o meio ambiente, de forma a permitir a compatibilidade entre este e o desenvolvimento econômico (RIBEIRO, 2006). Bonifácio, Campos e Tachibana (2003) reiteram que os passivos ambientais não necessariamente advêm de falhas do processo produtivo ou de uma gestão administrativa falha perante as questões ambientais, uma vez que podem ser originados do processo fim da empresa, como os processos extrativistas ou que utilizem grande quantidade de água potável em seus processos, por exemplo, a geração de resíduos.

\section{GESTÃo DE RESÍDUOS}

Dentro de uma empresa sempre haverá a geração de resíduos que causarão danos ao meio ambiente, mesmo havendo reutilização, redução e reciclagem. Por isso, faz-se necessário a melhor gestão possível, por meio da elaboração adequada de procedimentos e normatizações para o gerenciamento de tais resíduos. É importante que haja a participação de todos os colaboradores, por meio de ampla mobilização, e a elaboração de um Sistema Gerenciador Interno dos Resíduos Sólidos, que conterá a determinação dos procedimentos, os setores responsáveis, as metodologias de segregação na origem, as formas de acondicionamento e transporte, além de confecção de planilhas de controle de resíduos (NAIME, 2005). 
Weitz et al. (2002) corroboram que o gerenciamento dos resíduos requer decisões complexas em relação à maneira de coletar, reciclar, transportar e ainda descartar tais resíduos, que podem, ao mesmo tempo, influenciar os custos incorridos no processo, bem como os riscos ambientais. No entanto, os avanços tecnológicos, os regulamentos ambientais e a ênfase na conservação e recuperação dos recursos reduzem os impactos ambientais relacionados aos resíduos. Além disso, Santos, Stevens e Gonçalves (2016) observaram, em sua pesquisa, que os resíduos são considerados o maior passivo ambiental, e que as empresas estudam maneiras de viabilizar a geração de receita financeira, por meio da reciclagem desses resíduos.

Nesse contexto, Saidelles et al. (2012) orientam que para as empresas que não reaproveitam seus resíduos, o passo inicial é justamente o mapeamento de resíduos gerados no processo, uma vez que essa prática é o passo inicial para a introdução de um sistema de gestão ambiental. Os referidos autores sinalizam que a reutilização dos resíduos também possibilita a redução do impacto ambiental causado e gera uma economia decorrente da redução dos custos de produção, uma vez que os resíduos retornam ao processo produtivo sob a forma de matéria-prima.

Em relação à gestão ambiental, Barbieri (2004, p. 20) elucida que ela se refere às “diretrizes e atividades administrativas e operacionais, tais como planejamento, direção, controle e alocação de recursos” realizadas com o objetivo de obter efeitos positivos sobre o meio ambiente, seja para reduzir ou eliminar os danos, resíduos ou problemas causados pelas ações humanas, seja para evitar que eles surjam. Seiffert (2005, p. 24) ressalta que gestão ambiental diz respeito ao processo adaptativo, por meio “do qual as organizações definem e redefinem seus objetivos e metas relacionadas à proteção do ambiente", selecionando estratégias para atingir esses objetivos em um tempo determinado, por meio de constante avaliação de sua interação com o meio ambiente externo.

Conforme Paulella e Scapim (1996), a gestão de resíduos deve estar alicerçada em condições ambientais adequadas, em que sejam considerados todos os aspectos envolvidos, desde a fonte geradora até a disposição segura, assim como os aspectos de reciclagem máxima dos resíduos, buscando, inclusive, incorporar as mudanças dos padrões de produção e consumo. Na busca pela minimização de descarte de substâncias na natureza e também pela redução do consumo de recursos naturais, as organizações têm buscado reintegrar os resíduos nos processos produtivos originais por meio de reciclagem, reuso ou recuperação, permitindo, assim, o desenvolvimento sustentável e a redução de passivos ambientais ou destinação desses resíduos a outros processos de produção (HODGE; OCHSENDORF; FERNÁNDEZ, 2010). 
No Brasil, um passo importante no sentido de regulamentar a responsabilidade no que se refere aos resíduos sólidos foi a Lei n. 12.305, de 02 de agosto de 2010, que instituiu a Política Nacional de Resíduos Sólidos (PNRS). Os objetivos da PNRS consistem na não geração, redução, reutilização e tratamento de resíduos sólidos; na destinação final ambientalmente correta dos resíduos; na redução do uso dos recursos naturais no processo produtivo; na intensificação da educação ambiental; no aumento da reciclagem; na promoção da inclusão social e na geração de emprego e renda para catadores de materiais recicláveis (BRASIL, 2010).

De acordo com o Instituto de Pesquisa Econômica Aplicada (IPEA) (2012), um grande desafio para a implementação e o cumprimento das diretrizes da PNRS é, justamente, promover a mudança de cultura das empresas, de forma que extrapolem a conduta negligente ou reativa, passando a assumir uma conduta mais responsável, caracterizada por uma abordagem mais proativa. Com a PNRS, a destinação dos resíduos industriais passa a ser obrigação do gerador, podendo ele próprio executar esse papel (tratamento interno) ou contratar serviços de empresas especializadas (BRASIL, 2010).

\section{METODOLOGIA}

Nesta pesquisa realizou-se uma survey, por meio do questionário construído à luz de vertentes teóricas revisadas. Manteve-se o sigilo dos respondentes, bem como a razão social das empresas participantes. Bell (2008) e Cervo, Bervian e Silva (2011) recomendam o anonimato, a fim de que os participantes se sintam mais à vontade para responder o questionário, possibilitando a obtenção de respostas mais verdadeiras.

O questionário foi construído com questões fechadas, utilizando a escala Likert de cinco pontos. Essa técnica consiste em um conjunto de afirmações nas quais o respondente demonstra sua opinião em um sistema de cinco categorias de resposta, que variam de "discordo totalmente” a "concordo totalmente”. Também fizeram parte do questionário questões que envolveram valores monetários, nas quais foram utilizadas sugestões de valores em moeda corrente nacional (real) para identificar os custos e os investimentos ambientais anuais das empresas. Para a elaboração das questões, evitou-se questionar valores exatos de custos, sugerindo faixas de valores.

A etapa de validação do questionário ocorreu por meio da técnica Delphi, que é definida como um método sistematizado de julgamento de informações, destinada para obter consenso de especialistas, por meio de validações articuladas em fases denominadas rodadas de revisão do questionário (WRIGHT; JOHNSON; BIAZZI, 1991). A seleção dos experts é considerada não aleatória, por conveniência e inten- 
cional e se justifica uma vez que o interesse é selecionar especialistas na temática de estudo (GIOVINAZZO, 2001). Nesse sentido, escolheram-se cinco experts da área para compor o grupo de especialistas.

Concluída a etapa de validação do questionário, determinou-se a população do estudo. No Brasil, em decorrência das dificuldades de acessos aos bancos de dados, tem-se utilizado o critério de conveniência para a seleção da população em razão da facilidade de acesso proporcionada por entidades representativas de empresas (PERIN, 2001). No caso deste estudo, estabeleceu-se que o universo da pesquisa seriam empresas associadas à Federação das Indústrias do Estado do Rio Grande do Sul (FIERGS) (2013).

Dessa forma, o universo foi constituído de 186 indústrias químicas localizadas na região Metropolitana de Porto Alegre, no Estado do Rio Grande do Sul, e obteve-se resposta de 36 colaboradores; essa amostragem se caracteriza como não probabilística e por conveniência, uma vez que o entrevistado tem o direito de optar por não responder à pesquisa, tornando sua participação facultativa. Os dados foram coletados por meio de entrevistas telefônicas, pela equipe de entrevistadores do Centro de Pesquisa e Planejamento (CPP) da Universidade Feevale, no período de 16 de junho a 16 de julho de 2015. A Tabela 1 ilustra detalhadamente a distribuição das empresas por cidade pesquisada.

Tabela 1 - Localização das empresas

\begin{tabular}{|c|c|}
\hline Cidade & Quantidade de empresas \\
\hline Novo Hamburgo & 9 \\
\hline Canoas & 5 \\
\hline Portão & 4 \\
\hline São Leopoldo & 4 \\
\hline Alvorada & 3 \\
\hline Porto Alegre & 2 \\
\hline Sapiranga & 2 \\
\hline Cachoeirinha & 2 \\
\hline Estância Velha & 1 \\
\hline Campo Bom & 1 \\
\hline Ivoti & 1 \\
\hline Dois Irmãos & 1 \\
\hline Triunfo & 1 \\
\hline Total & 36 \\
\hline
\end{tabular}


Em relação ao perfil da empresa, 21 destas são microempresas, 11 são pequenas empresas, e quatro, médias empresas. Destaca-se que, para a classificação das empresas quanto ao porte, utilizou-se o critério de número de empregados, conforme proposto pelo Serviço Brasileiro de Apoio à Micro e Pequena Empresa (Sebrae). Assim, as empresas classificam-se da seguinte forma:

a) micro: empresas que possuem até 19 vínculos ativos;

b) pequena: empresas que possuem de 20 a 99 vínculos ativos;

c) média: empresas que possuem de 100 a 499 vínculos ativos;

d) grande: empresas que possuem 500 ou mais vínculos ativos (SERVIÇO BRASILEIRO DE APOIO ÀS MICRO E PEQUENAS EMPRESAS, 2014).

No que diz respeito ao tempo de funcionamento das organizações pesquisadas, constata-se que 12 empresas têm entre 20 e 25 anos de fundação, 11 têm até 19 anos, sete têm mais de 35 anos, três têm entre 26 e 30 anos, duas têm entre 31 e 35 anos e uma delas não informou seu tempo de atuação. O tempo de atuação prevalente entre 20 e 25 anos aponta para empresas com tradição no mercado. Em relação ao perfil dos entrevistados, oito são químicos, sete administradores, quatro engenheiros, dois compradores, dois farmacêuticos, dois técnicos em curtimento, dois técnicos em segurança do trabalho, dois técnicos químicos, sendo os demais ocupantes de cargo administrativo.

\section{ANÁLISE DOS RESULTADOS}

Inicialmente, buscou-se identificar a presença de um setor de qualidade ambiental. Constatou-se que 24 das empresas investigadas não possuem o referido setor, ao passo que 12 empresas mantêm esse setor na sua estrutura organizacional. Por outro lado, 20 dos entrevistados sinalizaram que em suas empresas existe a presença de consultoria externa para auxiliar nas questões ambientais. Entretanto, as outras 16 empresas não contam com esse auxílio externo, o que reflete o comportamento da maioria das organizações, que prefere contratar técnicos externamente do que mantê-los nos seus quadros de colaboradores.

Buscou-se, ainda, identificar se as empresas estudadas possuem um controle contábil de seus passivos ambientais, considerando a importância da contabilidade no inter-relacionamento da empresa com o meio ambiente, citada por Tinoco e Kraemer 
(2011). Constatou-se que 25 das empresas mantêm esse controle, enquanto 11 delas não o possuem. Cabe lembrar que passivos ambientais se referem aos benefícios econômicos ou aos resultados que serão sacrificados em razão da necessidade de preservar, proteger e recuperar o meio ambiente, a fim de permitir a compatibilidade entre este e o desenvolvimento econômico (RIBEIRO, 2006).

Destarte, investigaram-se os valores desembolsados pelas empresas às atividades de proteção do meio ambiente, mais especificamente o valor aplicado à proteção e recuperação do solo, das águas e do ar. Nesse tópico da pesquisa constatou-se que em 23 empresas o valor gasto é de até R\$10.000,00, enquanto que três empresas gastam na faixa de R $\$ 10.000,01$ a $\mathrm{R} \$ 50.000,00$, e somente um entrevistado declarou gastos na faixa de $\mathrm{R} \$ 50.000,01$ a $\mathrm{R} \$ 200.000,00$. Contudo, nove dos entrevistados não souberam ou não quiseram fornecer essa informação.

De acordo com Bonifácio, Campos e Tachibana (2003), não necessariamente os passivos ambientais são gerados a partir de falhas de condução do processo produtivo ou de uma gestão administrativa falha perante as questões ambientais, uma vez que podem decorrer do processo fim da empresa. Assim, os resíduos gerados ao final do processo produtivo são considerados passivos ambientais. Para Naime (2005), sempre haverá a geração de resíduos que causarão danos ao meio ambiente; por esse motivo, faz-se necessária a gestão de resíduos por meio da elaboração de procedimentos e normatizações para o gerenciamento destes.

Entre as empresas investigadas, constatou-se que o dispêndio anual com a gestão de resíduos de 18 delas situa-se em até $\mathrm{R} \$ 10.000,00$, ao passo que sete sinalizaram um gasto entre $\mathrm{R} \$ 10.000,01$ e $\mathrm{R} \$$ 50.000,00 e quatro despendem de $\mathrm{R} \$$ $50.000,01$ a R\$ 200.000,00. As outras sete não souberam ou não quiseram informar o valor gasto com a gestão de resíduos. Cumpre destacar que, assim como exposto por Santos, Stevens e Gonçalves (2016), os resíduos foram identificados como a maior parte dos passivos ambientais nas empresas analisadas, além disso, metade da amostra declarou tratar seus próprios passivos ambientais.

Nesse sentido, evidenciou-se que 21 das empresas comercializam os resíduos gerados pelo processo produtivo a fim de obterem receita adicional, ao passo que 15 empresas não possuem essa prática. Com base na resposta positiva de 58,3\% das empresas estudadas, pode-se afirmar que as indústrias químicas localizadas na região Metropolitana de Porto Alegre, de modo geral, conscientizaram-se que podem obter retorno financeiro por meio do gerenciamento de resíduos e, consequentemente, diminuição dos impactos ambientais ligados à destinação deles, o que também acarreta 
benefícios mercadológicos decorrentes do melhor posicionamento da imagem da empresa no mercado, conforme apontam Sanches (1997) e Leonardo (2006).

Ademais, 24 entrevistados declararam que os resíduos sólidos gerados em um processo produtivo são reaproveitados na produção de outro produto, ao passo que 12 entre os entrevistados sinalizaram que não fazem uso do reaproveitamento dos resíduos, seja em razão da invalidade operacional, seja por não possuírem o mapeamento dos resíduos sólidos gerados no processo. Cumpre destacar que Saidelles et al. (2012) advertem sobre a importância de as empresas mapearem os resíduos gerados durante o processo produtivo, uma vez que a referida análise viabiliza a possibilidade de reaproveitamento dos resíduos sob forma de matéria-prima, que, por sua vez, acarreta a redução do impacto ambiental e economias decorrentes da redução dos custos de produção.

Outro item sinalizado por Weitz et al. (2002) como imprescindível no gerenciamento de resíduos diz respeito à maneira de transportar os resíduos, uma vez que esse processo afeta os custos e as emissões ambientais. Nesse tópico de análise, constatou-se que 33 das empresas possuem o controle dos resíduos transportados e, consequentemente, dos custos advindos desse processo, três empresas não controlam. Além disso, 34 dos 36 entrevistados apontaram que os resíduos estocados ou transportados são claramente identificados.

Em relação à comunicação interna, constatou-se que 19 das 36 empresas comunicam aos seus colaboradores a existência dos passivos ambientais, enquanto 17 delas não o fazem. Vale destacar que Moura (2006) adverte que a empresa terá sucesso quanto à gestão de custos ambientais somente quando contar com o envolvimento e o comprometimento de todos os colaboradores e a alta direção nas áreas de gestão ambiental, finanças e contabilidade. No que diz respeito à preocupação da diretoria com os passivos ambientais, 30 entrevistados afirmaram existir essa preocupação por parte da diretoria para diminuir ou eliminar os passivos ambientais, sendo apenas seis as empresas que não possuem essa preocupação.

Em termos de legislação, 25 entrevistados sinalizaram ter conhecimento da Lei n. 12.305, de 02 de agosto de 2010, que institui a Política Nacional de Resíduos Sólidos, visto que 11 informaram desconhecer a referida norma legal. Além disso, constatou-se que o valor despendido em multas ambientais no ano 2014 para 25 das empresas investigadas se concentrou na faixa de até R\$10.000,00, e um entrevistado sinalizou gasto entre $\mathrm{R} \$ 10.000,01$ e $\mathrm{R} \$ 50.000,00$, ao passo que 10 entrevistados não souberam ou não quiseram informar. 
Considerando a necessidade de todos os colaboradores estarem engajados com a gestão dos custos ambientais (MOURA, 2006), a fim de tornarem a organização ambientalmente eficiente (SANCHES, 1997), aliada ao fato de a indústria química ser considerada um setor de alto potencial poluidor (LEONARDO, 2006), acredita-se, com base nos dados analisados, que as indústrias do referido setor precisam adotar a educação ambiental, a fim de melhor conscientizar os colaborares sobre a questão dos impactos ambientais. Tal constatação refere-se ao fato de que os entrevistados apontaram que os resíduos são os maiores passivos ambientais de suas empresas, e 30,6\% dos entrevistados desconhecem a Lei n. 12.305, principal marco legal que institui a Política Nacional de Resíduos Sólidos.

Sucintamente, as empresas pesquisadas consideram investimentos os dispêndios destinados à área ambiental, e seus planejamentos estratégicos incorporam a perspectiva de desenvolvimento sustentável, preocupando-se com a manutenção de estoques de recursos naturais, a qualidade de vida e o uso adequado do solo, além do aspecto da conservação e sistemas naturais. Os entrevistados enfatizaram a importância de uma adequada gestão de custos, em razão da preocupação de evitar passivos ambientais e principalmente por refletir no preço de venda do produto. Assim, pode-se concluir que a questão financeira é o principal fator motivador para a adoção de práticas ambientalmente sustentáveis nas indústrias químicas da região metropolitana de Porto Alegre.

\section{CONSIDERAÇÕES FINAIS}

O objetivo geral com esta pesquisa foi analisar os custos ambientais relacionados com a gestão de resíduos em indústrias químicas localizadas na região metropolitana de Porto Alegre. Com base nos dados analisadas, constatou-se que as referidas empresas se preocupam em manter uma adequada gestão de custos, seja pela preocupação em evitar passivos ambientais, controle de resíduos existentes, seja pelo reflexo que os custos ambientais possuem sobre o preço de venda dos produtos. Além disso, os resultados facultaram a constatação de que os valores investidos pela maioria das organizações pesquisadas se situam na faixa de até R\$10.000,00, limitados pelo porte das empresas que, na amostra deste estudo, são micro ou pequenas.

De modo geral, foi possível constatar que as empresas possuem consciência de que podem obter retorno financeiro por meio do gerenciamento de resíduos e, consequentemente, diminuir os impactos ambientais ligados à destinação deles, o que também acarreta benefícios mercadológicos decorrentes do melhor posicionamento 
da imagem da empresa no mercado. Contudo, identificou-se uma série de fatores que obstaculizam o referido processo, com destaque para as deficiências na comunicação aos colaboradores no que diz respeito ao principal marco legal destinado à gestão de resíduos no Brasil, uma vez que os padrões ali descritos tendem a melhorar a efetividade operacional, por meio da redução dos impactos ambientais.

Ainda que com esta pesquisa se tenham atingido os objetivos propostos e que o rigor metodológico tenha sido perseguido, não se pode ignorar a existência de limitações que podem contribuir para indicar possibilidades de realização de novos estudos. A primeira limitação consiste na elaboração de uma pesquisa com a abordagem quantitativa, com a utilização da escala tipo Likert, no instrumento de coleta de dados, uma vez que essa técnica apenas registra o nível de concordância ou discordância em relação a uma afirmativa formulada pelos pesquisadores, com base na revisão teórica, realizada previamente. Além disso, como foi indagado apenas um colaborador de cada empresa, deve ser considerado o viés do respondente, bem como o reducionismo da realidade, que é a característica da pesquisa do tipo survey.

Destaca-se, ainda, a limitação de ordem operacional, visto que o banco de dados utilizado considera apenas o cadastro das empresas registradas no sistema da FIERGS. Como o cadastramento no sistema é realizado por iniciativa das empresas, acredita-se que muitas delas podem não ter sido consideradas, para efeito do cálculo amostral. Entretanto, apesar dessa limitação, é possível afirmar que a referida base de dados é a melhor e mais completa do Estado.

Como sugestão para trabalhos futuros, recomenda-se uma análise do ganho econômico advindo do reaproveitamento dos resíduos, seja pela reintegração dele no processo produtivo, seja pela comercialização deste e sua representatividade em relação à receita total e ao resultado do exercício.

\section{REFERÊNCIAS}

ASSOCIAÇÃO BRASILEIRA DA INDÚSTRIA QUÍMICA. Desempenho da Indústria Química Brasileira. São Paulo, 2015. Disponível em: <http://www. abiquim.org.br/pdf/livreto-de-dados-2015-paginas.pdf>. Acesso em: 14 jun. 2016.

BARBIERI, J. C. Gestão ambiental empresarial: conceitos, modelos e instrumentos. São Paulo: Saraiva, 2004. 328 p.

BELL, J. Como realizar um projeto de investigação: um guia para pesquisa em ciências sociais e da educação. 4. ed. Lisboa: Gradiva, 2008. 245 p. 
BONIFÁCIO, M. A.; CAMPOS, F. C.; TACHIBANA, W. K. Manutenção industrial: uma estratégia para redução do passivo ambiental. 2003. Disponível em: <http:// www.anpad.org.br/diversos/trabalhos/3Es/3es_2003/2003_3ES12.pdf>. Acesso em: 13 ago. 2016.

BRASIL. Lei n. 12.305, de 02 de agosto de 2010. Institui a Política Nacional de Resíduos Sólidos; altera a Lei n. 9.605, de 12 de fevereiro de 1998; e dá outras providências. Diário Oficial da União, Brasília, DF, 03 ago. 2010. Disponível em: <http://www.planalto.gov.br/ccivil_03/_ato2007-2010/2010/lei/112305.htm>. Acesso em: 13 ago. 2016.

CERVO, A. L.; BERVIAN, P. A.; SILVA, R. Metodologia científica. 6. ed. São Paulo: Pearson Prentice Hall, 2011. 162 p.

FEDERAÇÃO DAS INDÚSTRIAS DO ESTADO DO RIO GRANDE DO SUL. Cadastro Industrial do Rio Grande do Sul. Porto Alegre: Unidade de Estudos Técnicos: Sistema FIERGS, 2013. 1 CD-ROM.

FREITAS, J. L. et al. Custo ambiental: uma abordagem sobre o conceito e sua aplicação em uma indústria no processo de microfusão de aço. In: CONGRESSO BRASILEIRO DE CUSTOS, 14., 2007, João Pessoa. Anais... João Pessoa: ABCUSTOS, 2007.

GIOVINAZZO, R. A. Modelo de Aplicação da Metodologia Delphi pela Internet: Vantagens e Ressalvas. Revista Administração Online, São Paulo: FECAP, v. 2, n. 2, abr./jun. 2001. Disponível em: <http://www.fecap.br/adm_online/ art22/renata. htm>. Acesso em: 27 jul. 2014.

HODGE, M.; OCHSENDORF, J.; FERNÁNDEZ, J. Quantifying potential profit from material recycling: a case study in brick manufacturing. Journal of Cleaner production, v. 18, i. 12, p. 1190- 1199, 2010.

INSTITUTO DE PESQUISA ECONÔMICA APLICADA. Caderno de Diagnóstico: Resíduos Sólidos Industriais. 2012. Disponível em: <http://www.ipea.gov.br/ agencia/images/stories/PDFs/relatoriopesquisa/121009_relatorio_residuos_solidos_ urbanos.pdf>. Acesso em: 13 ago. 2016.

LEONARDO, V. S. Um estudo sobre os gastos ambientais presentes na contabilidade de indústrias químicas brasileiras. Contabilidade Vista \& Revista, Belo Horizonte, v. 17, n. 2, p. 89-109, abr./jun. 2006. 
LEONE, G. S. G.; LEONE, R. J. G. Curso de contabilidade de custos. 4. ed. São Paulo: Atlas, 2010.

MOURA, L. A. A. Economia ambiental: gestão de custos e investimentos. 3. ed. São Paulo: Juarez de Oliveira, 2006.

MOURA, L. A. A. Qualidade \& Gestão Ambiental. 4. ed. São Paulo: Juarez de Oliveira, 2004.

NAIME, R. Diagnóstico ambiental e sistemas de gestão ambiental: incluindo a atualização da série ISO 9000 e suas NBR 14001/2004 e NBR ISO 19011/2002. Novo Hamburgo: Feevale, 2005.

PAULELLA, E. D.; SCAPIM, C. O. A gestão dos resíduos sólidos urbanos.

Campinas: Secretaria de Serviços Públicos: Secretaria da Administração, 1996.

PERIN, M. G. A Relação entre orientação para mercado, aprendizagem organizacional e performance. 2001. 194 p. Tese (Doutorado em Administração)-Universidade Federal do Rio Grande do Sul, Porto Alegre, 2001.

RIBEIRO, M. S. Contabilidade ambiental. São Paulo: Saraiva, 2006.

SAIDELLES, A. P. F. et al. Gestão de resíduos sólidos na indústria de beneficiamento de arroz. Revista Eletrônica em Gestão, Educação e Tecnologia Ambiental, Santa Maria, v. 5, n. 5, p. 904-916, 2012.

SANCHES, C. S. Mecanismos de interiorização dos custos ambientais na indústria: rumo a mudanças de comportamento. Revista de Administração de Empresas, v. 37, n. 2, p. 56-67. abr./jun. 1997.

SANTOS, C.; STEVENS, D.; GONÇALVES, C. V. Caracterização e gerenciamento de resíduos sólidos em uma indústria alimentícia. Disponível em: <https:// www.univates.br/tecnicos/media/artigos/Caroline_Sartori_dos_Santos_Debora_Stevens_e_Catia_Viviane_Goncalves.pdf>. Acesso em: 20 jan. 2016.

SEIFFERT, M.; BERNADINI, E. ISO 14001: Sistemas de Gestão Ambiental. São Paulo: Atlas, 2005. 256 p.

SERVIÇO BRASILEIRO DE APOIO ÀS MICRO E PEQUENAS EMPRESAS. Critério de Classificação de empresas: EI - ME - EPP. Disponível em: <http:// www.sebrae-sc.com.br/leis/default.asp?vcdtexto=4154>. Acesso em: 02 jul. 2014. 
SILVA, B. A. Contabilidade e meio ambiente: considerações teóricas e práticas sobre o controle dos gastos ambientais. São Paulo: Annablume, 2009.

TINOCO, J. E. P.; KRAEMER, M. E. P. Contabilidade e gestão ambiental. São Paulo: Atlas, 2011.

WAKIM, V. R.; WAKIM, E. A. M. Perícia contábil e ambiental: fundamentação e prática. São Paulo: Atlas, 2012.

WEITZ, K. A. et al. The impact of municipal solid waste management on greenhouse gas emissions in the United States. Journal of the Air, Waste Management Association, v. 52, i. 9, p. 1000-1011, 2002.

WRIGHT, J. T. C.; JOHNSON, B. B.; BIAZZI, J. L. O uso da técnica Delphi na elaboração de cenários. São Paulo: PETROBRAS, 1991. 31 p.

\section{Como citar este artigo:}

\section{ABNT}

MORAES, Margareth Aparecida et al. Análise dos custos ambientais relacionados com a gestão de resíduos em indústrias químicas. RACE, Revista de Administração, Contabilidade e Economia, Joaçaba: Ed. Unoesc, v. 16, n. 2, p. 505-522, maio/ago. 2017. Disponível em: <http://editora.unoesc.edu.br/index.php/race>. Acesso em: dia/mês/ano.

\section{APA}

Moraes, M. A., Theis, V., Vier, M. B., \& Schreiber, D. (2017). Análise dos custos ambientais relacionados com a gestão de resíduos em indústrias químicas. RACE, Revista de Administração, Contabilidade e Economia, 16(2), 505-522. Recuperado em dia/mês/ano, de http://editora.unoesc.edu.br/index.php/race 
